\title{
Evaluation of Xpert Carba-R Assay for the Detection of Carbapenemase Genes in Gram-Negative Bacteria
}

\author{
Hou-He Li, ${ }^{1,2}$ Zhi-Jian He, ${ }^{1,2}$ Li-Min Xie, ${ }^{1,2}$ Jin-Sheng Zhang, ${ }^{1,2}$ Tian-Ao Xie,, \\ Shu-Jin Fan, 1,2 and Xu-Guang Guo iD $1,2,3,4,5$ \\ ${ }^{1}$ Department of Clinical Laboratory Medicine, The Third Affiliated Hospital of Guangzhou Medical University, \\ Guangzhou 510150, China \\ ${ }^{2}$ Department of Clinical Medicine, The Third Clinical School of Guangzhou Medical University, Guangzhou 511436, China \\ ${ }^{3}$ Key Laboratory for Major Obstetric Diseases of Guangdong Province, The Third Clinical School of Guangzhou Medical University, \\ Guangzhou 510150, China \\ ${ }^{4}$ Key Laboratory of Reproduction and Genetics of Guangdong Higher Education Institutes, The Third Clinical School of Guangzhou \\ Medical University, Guangzhou 510150, China \\ ${ }^{5}$ Stomatological Hospital of Guangzhou Medical University, 510150, China
}

Correspondence should be addressed to Xu-Guang Guo; gysygxg@gmail.com

Received 3 November 2020; Revised 23 January 2021; Accepted 19 March 2021; Published 8 April 2021

Academic Editor: Marcelo A. Soares

Copyright (c) $2021 \mathrm{Hou}-\mathrm{He} \mathrm{Li} \mathrm{et} \mathrm{al.} \mathrm{This} \mathrm{is} \mathrm{an} \mathrm{open} \mathrm{access} \mathrm{article} \mathrm{distributed} \mathrm{under} \mathrm{the} \mathrm{Creative} \mathrm{Commons} \mathrm{Attribution} \mathrm{License,}$ which permits unrestricted use, distribution, and reproduction in any medium, provided the original work is properly cited.

\begin{abstract}
Introduction. High mortality associated with carbapenemase-producing Gram-negative bacteria (CP-GNB) has evolved into a global health threat. Rapid and accurate detection as well as prompt treatment are of great significance in this case. Xpert Carba$\mathrm{R}$, a multiple qualitative analysis designed to detect five clinically relevant carbapenem-resistant gene families within one hour, is regarded as reliable, accurate, and easy-to-operate. This study is to present a systematic evaluation of the performance of Xpert Carba-R in detecting carbapenemase genes in GNB suspected for carbapenemase production. Methods. We searched and screened the literature on "Xpert Carba-R" in the database of PubMed, Web of Science, Embase, and Cochrane Library, employing two independent evaluators to collect data, respectively. Then, statistical analysis of the data obtained was performed by the Stata 12.0 software to measure the accuracy of Xpert Carba-R assay in detecting the carbapenemase genes in GNB. Results. We screened a total of 1767 Gram-negative bacillus isolates documented in 9 articles. The precision of the detection of OXA-48 carbapenemase genes was $100 \%$; that of $\mathrm{NDM}=100 \%$; that of $\mathrm{VIM}=100 \%$. When it came to KPC, the precision rate was $100 \%$; that of IMP $=99 \%$. The overall accuracy of the detection of carbapenemase genes was $100 \%$. Conclusions. Xpert Carba- $\mathrm{R}$ assay demonstrates a $100 \%$ precision in identifying carbapenemase genes in GNB. It can be seen that Xpert Carba- $\mathrm{R}$ method is an effective tool for early clinical detection, which is suitable for the detection of carbapenase gene in GNB.
\end{abstract}

\section{Introduction}

The main mechanism of carbapenem resistance of Gramnegative bacteria (GNB) is the production of carbapenemase, which hydrolyzes many types of antibiotics (carbapenems, cephalosporins, penicillins, and aztreonam) $[1,2]$. Early in 2005, Walsh et al. specifically pointed out that the continuous spread of carbapenem-resistant Gram-negative bacteria (CR-GNB) worldwide will lead to clinical disasters and perhaps future public health crises [3]. Among them, carbapenem-resistant Enterobacteriaceae (CRE) especially has stand out from the crowd in that they are resistant to a great variety of drugs. Report had it that CRE caused 9,000 infections and 600 deaths each year in the United States [4, 5]. Currently, the dramatic increase in the prevalence and clinical impact of infections caused by carbapenemaseproducing Gram-negative bacteria (CP-GNB) has snowballed into a global health concern for the invasive infection of these bacteria is inextricably associated with a high mortality rate $[1,6]$.

Currently, phenotypic methods are often used to detect carbapenemase resistance in Gram-negative bacteria in 
TABLE 1: Literature inclusion and exclusion criteria.

Inclusion criteria(according to the "PICOS" standard)

Exclusion criteria

(1) Research object: Gram-negative bacteria

(2) Research type: accuracy test, to extract data for identifying carbapenemase genes, only in the English language

(3) Measurement indicators: detection rate

(4) Diagnostic experimental methods: Xpert Carba-R assay was used to detect carbapenemase genes in GNB

clinical laboratories, and to explore the molecular basis of carbapenemase resistance [7, 8]. The modified Hodge test (mHT), as a good case in point, is still frequently employed in detecting carbapenem product of GNB, which is, however, condemned as not desirable for disease control and treatment as it is time-consuming and severely limited by both the specificity and sensitivity in analysis.

Xpert Carba-R assay, a PCR-based test run on the GeneXpert platform, is designed for the rapid detection and differentiation of 5 carbapenemase genes (blaKPC, blaIMP, blaNDM, blaVIM, and blaOXA-48-like) [9]. The operation of Xpert Carba-R assay requires only 2 simple steps that could be completed within 1 hour, with less than 1 minute of hands-on time. As instructed by the manufacturer, researchers add $10 \mu \mathrm{L}$ solution of $0.5 \mathrm{~L} \mathrm{McF}$ standard suspension of the sample to a $5 \mathrm{~mL}$ Xpert Carba-R sample reagent vial and mix for 10 seconds. Through the supplied pipette, the sample reagents were added to the Xpert Carba- $\mathrm{R}$ kit and analyzed by the Cepheid GeneXpert platform [10, 11]. The result proves Xpert Carba- $\mathrm{R}$ analysis a reliable, accurate, and easy-to-use multiple qualitative analytic tool that is able to detect five clinically relevant carbapenemase gene families directly from the rectal swabs, which takes reduced time comparing with other culture-based methods for the identification of patients with gastrointestinal colonization of carbapenem-resistant organisms (CPO) $[12,13]$. The purpose of this study is to evaluate the performance of Xpert Carba- $\mathrm{R}$ assay in detecting carbapenemase genes in GNB, thereby providing a good epidemiological tool and a reference standard for clinical diagnosis.

\section{Materials and Methods}

2.1. Study Design and Literature Review Strategy. The research was scheduled from October 2019 to the present time, designed to be a systematic evaluation of the accuracy of Xpert Carba-R assay in the identification of carbapenemase genes.

We searched four databases, namely, PubMed, Web of Science, Embase, and Cochrane Library, with the keywords "Xpert Carba-R assay." Articles published before October 2019 were collected and imported into the EndNoteX9 software for file management. At the same time, we have also formulated the corresponding inclusion and exclusion criteria (Table 1).

2.2. Literature Screening and Data Extraction. All literature was screened according to the exclusion and inclusion criteria established previously, and a PRISMA flowchart was formed. The EndNoteX9 software was employed only for document management, and the information of each published study, including the author, year of publication, region, and other related information, was also extracted and included into a table for presentation.

2.3. Quality Evaluation of Literature. QUADAS-2 [13] worked as the instrument for quality appraisal, which was evaluated by two raters independently. Should the result reveals any inconsistency, it would subject to the discussion with a third person in the group.

2.4. Statistical Analysis. The main index of the performance of Xpert Carba-R assay is the accuracy in the determination of carbapenemase genes in GNB, which would be presented by the statistics processed by the Stata 12.0 software. Moreover, the $I^{2}$ value reveals the heterogeneity of researches in a way that a greater $I^{2}$ value indicates a higher heterogeneity. Should the heterogeneity be great enough, an additional subgroup analysis of the previously included studies would be performed to investigate the amount and extent of the effect that the suspected factors contribute to the heterogeneity. The data adopted to examine the levels of GNB from each study would generate an impact on the aggregate effect as a whole so that we did an impact analysis. The included studies were evaluated for publication bias with the Egger's test.

\section{Result}

3.1. Data Screening and Inclusion. We had a thorough search over the database of PubMed, Web of Science, Embase, and Cochrane Library with words, terms, and sentences related to this study. 44 articles were selected out from PubMed, 47 from Web of Science, 72 from Embase, and none from Cochrane Library, i.e., 163 articles in total. No related articles were retrieved. Apart from 80 articles excluded for duplication, the remaining 83 articles were subject to a full-text screening, by means of which another parts of articles were excluded, including those that did not meet the gold standard, those that data could not be extracted from, and those unrelated to our research. Nine articles were finally included in our research, and a systematic analysis of them was conducted $[9,10,14-20]$.

Data of the performance of Xpert ${ }^{\circledR}$ Carba-R in detecting various types of carbapenemase genes were extracted from the 9 articles included and were summarized in Table 2, which demonstrated a high accuracy of Xpert Carba- $\mathrm{R}$ in the detection of carbapenemase genes. 
TABLE 2: The identification accuracy rate of species from included articles.

\begin{tabular}{|c|c|c|c|c|c|}
\hline Author & Year & Genotype & Total & Events & $\begin{array}{l}\text { Detection } \\
\text { rate }\end{array}$ \\
\hline \multirow{5}{*}{ Tato [9] } & 2016 & OXA-48 & 40 & 38 & $95 \%$ \\
\hline & 2016 & NDM & 26 & 26 & $100 \%$ \\
\hline & 2016 & VIM & 31 & 29 & $93.55 \%$ \\
\hline & 2016 & KPC & 30 & 29 & $96.67 \%$ \\
\hline & 2016 & IMP & 27 & 26 & $96.30 \%$ \\
\hline \multirow{5}{*}{ McMullen [10] } & 2017 & OXA-48 & 12 & 12 & $100 \%$ \\
\hline & 2017 & NDM & 27 & 27 & $100 \%$ \\
\hline & 2017 & VIM & 7 & 7 & $100 \%$ \\
\hline & 2017 & KPC & 84 & 84 & $100 \%$ \\
\hline & 2017 & IMP & 1 & 1 & $100 \%$ \\
\hline \multirow{5}{*}{ Moore [11] } & 2017 & OXA-48 & 113 & 111 & $98.23 \%$ \\
\hline & 2017 & NDM & 88 & 88 & $100 \%$ \\
\hline & 2017 & VIM & 92 & 87 & $94.57 \%$ \\
\hline & 2017 & $\mathrm{KPC}$ & 110 & 110 & $100 \%$ \\
\hline & 2017 & IMP & 80 & 76 & $95 \%$ \\
\hline \multirow{5}{*}{ Findlay [14] } & 2015 & OXA-48 & 100 & 100 & $100 \%$ \\
\hline & 2015 & NDM & 100 & 100 & $100 \%$ \\
\hline & 2015 & VIM & 100 & 100 & $100 \%$ \\
\hline & 2015 & KPC & 100 & 100 & $100 \%$ \\
\hline & 2015 & IMP & 24 & 17 & $71 \%$ \\
\hline \multirow{2}{*}{$\begin{array}{l}\text { Hoyos-Mallecot } \\
{[15]}\end{array}$} & 2017 & OXA-48 & 10 & 10 & $100 \%$ \\
\hline & 2017 & KPC & 1 & 1 & $100 \%$ \\
\hline \multirow{5}{*}{ Kost [16] } & 2017 & OXA-48 & 9 & 8 & $88.90 \%$ \\
\hline & 2017 & NDM & 25 & 25 & $100 \%$ \\
\hline & 2017 & VIM & 3 & 3 & $100 \%$ \\
\hline & 2017 & KPC & 43 & 41 & $95.30 \%$ \\
\hline & 2017 & IMP & 2 & 2 & $100 \%$ \\
\hline \multirow{5}{*}{ Vanstone [17] } & 2018 & OXA-48 & 24 & 24 & $100 \%$ \\
\hline & 2018 & NDM & 22 & 22 & $100 \%$ \\
\hline & 2018 & VIM & 19 & 19 & $100 \%$ \\
\hline & 2018 & KPC & 3 & 3 & $100 \%$ \\
\hline & 2018 & IMP & 1 & 1 & $100 \%$ \\
\hline \multirow{5}{*}{ Traczewski [18] } & 2018 & OXA-48 & 89 & 89 & $100 \%$ \\
\hline & 2018 & NDM & 78 & 78 & $100 \%$ \\
\hline & 2018 & VIM & 82 & 82 & $100 \%$ \\
\hline & 2018 & KPC & 84 & 84 & $100 \%$ \\
\hline & 2018 & IMP & 40 & 40 & $100 \%$ \\
\hline \multirow{5}{*}{ Cointe [19] } & 2019 & OXA-48 & 10 & 10 & $100 \%$ \\
\hline & 2019 & NDM & 11 & 11 & $100 \%$ \\
\hline & 2019 & VIM & 7 & 7 & $100 \%$ \\
\hline & 2019 & KPC & 10 & 10 & $100 \%$ \\
\hline & 2019 & IMP & 1 & 1 & $100 \%$ \\
\hline
\end{tabular}

3.2. Systematic Analysis. A total of 1767 Gram-negative bacilli in 9 articles were evaluated (Table 3), and the Stata software was employed to conduct a systematic review of the 9 articles, which was displayed in the form of a forest map (S1). At the same time, we also summarized the data characteristics of the included studies and presented them in Table 4 . The precision of the detection of OXA-48 carbapenemase gene was $100 \%$, with a $p$ value of 0.753 and an $I^{2}$ value of $0.0 \%$; that of $\mathrm{NDM}$ was $100 \%$, with a $p$ value of 1.000 and an $I^{2}$ value of $0.0 \%$; that of VIM was $100 \%$, with a $p$ value of 0.403 and an $I^{2}$ value of $3.5 \%$; that of KPC was $100 \%$, with the $p$ value being 0.931 and the $I^{2}$ value $0.0 \%$; that of IMP was $99 \%$, with the $p$ value being 0.039 and the $I^{2}$ value $52.6 \%$. The overall accuracy of the detection of carbapenemase genes was $100 \%$, with a $p$ value of 0.889 and an $I^{2}$ value of $0.0 \%$. The results are exhibited in Figure 1.

3.3. Sensitivity Analysis. Sensitivity analysis is designed to assess the impact of every one of the nine studies on the consolidated results of the systematic analysis by comparing the amount of the combined effect generated by the analysis excluding one of the 9 studies and that produced by the analysis of all studies included. On the left side, the vertical line represents the minimum value of the $95 \%$ confidence interval for the overall consolidation effect, and the vertical solid line on the right represents the maximum value for the $95 \%$ confidence interval for the overall consolidation effect. The overall effect is represented by a solid vertical middle line of 0.98 (0.92 and 1.05). The results are shown in Figure 2.

3.4. Publication Bias. As a matter of fact, there is a tendency to publish or report studies with results that support a hypothesis than those that do not so that the negative information obtained from the database may be unscientifically modulated, thereby causing systematic error, which is named publication bias. In order to have a good grip of the impact of publication bias on the literature review of this research, all data extracted from the articles included were processed into a funnel chart. The results of the combination of carbapenemase genes are displayed in Figure 3, with a $t$ value of -0.35 and a $p$ value of 0.728 .

\section{Discussion}

Since a national outbreak of a disease caused by carbapenemresistant Enterobacter (CRE) appeared in Israel in 2006 [20], how to address GNB's resistance to carbapenem antibiotics has become a heated topic in public health [21]. Rapid detection of CR-GNB infection or carbapenem resistance is of great significance to reduce the mortality rate [22]. Xpert Carba- $\mathrm{R}$ assay, as an emerging real-time PCR-based detection instrument, boasts short turnaround time ( $<1$ hour), simple and fast operation, high detection rate, and low cost [23]. Compared with the traditional PCR method that is still widely accepted as the gold standard, Xpert Carba-R assay is an important improvement in the diagnosis of diseases caused by CR-GNB.

The main purpose of this study was to demonstrate the performance of Xpert Carba- $\mathrm{R}$ assay for the determination of carbapenemase genes in GNB. Included in the study were the detection rates obtained by testing samples that had been previously confirmed by the gold standard. After strict 
TABLE 3: Characteristics of included articles.

\begin{tabular}{|c|c|c|c|c|c|c|c|c|c|c|}
\hline Arthur & Year & $\begin{array}{l}\text { Experiment } \\
\text { design }\end{array}$ & $\begin{array}{l}\text { Golden } \\
\text { standard }\end{array}$ & $\begin{array}{l}\text { Geographical } \\
\text { distribution } \\
\text { of strains }\end{array}$ & Source of samples & $\begin{array}{l}\text { Total } \\
\text { sample }\end{array}$ & Genotype & Total & Events & $\begin{array}{l}\text { Detection } \\
\text { rate }\end{array}$ \\
\hline \multirow{5}{*}{ Tato [9] } & \multirow{5}{*}{2016} & \multirow{5}{*}{ prospective } & \multirow{5}{*}{$\begin{array}{l}\text { culture and } \\
\text { sequence }\end{array}$} & \multirow{5}{*}{ UK } & \multirow{5}{*}{$\begin{array}{c}383 \text { clinical isolates } \\
\text { and } 250 \text { contrived } \\
\text { isolates }\end{array}$} & \multirow{5}{*}{633} & OXA-48 & 40 & 38 & $95 \%$ \\
\hline & & & & & & & NDM & 26 & 26 & $100 \%$ \\
\hline & & & & & & & VIM & 31 & 29 & $93.55 \%$ \\
\hline & & & & & & & KPC & 30 & 29 & $96.67 \%$ \\
\hline & & & & & & & IMP & 27 & 26 & $96.30 \%$ \\
\hline \multirow{5}{*}{$\begin{array}{l}\text { McMullen } \\
{[10]}\end{array}$} & \multirow{5}{*}{2017} & \multirow{5}{*}{ retrospective } & \multirow{5}{*}{$\begin{array}{c}\text { laboratory- } \\
\text { developed PCR } \\
\text { assays or must } \\
\text { have been } \\
\text { previously } \\
\text { characterized as } \\
\text { part of the CDC }\end{array}$} & \multirow{5}{*}{$\begin{array}{l}\text { USA, UK and } \\
\text { Spain }\end{array}$} & \multirow{5}{*}{189 clinical isolates } & \multirow{5}{*}{189} & OXA-48 & 12 & 12 & $100 \%$ \\
\hline & & & & & & & NDM & 27 & 27 & $100 \%$ \\
\hline & & & & & & & VIM & 7 & 7 & $100 \%$ \\
\hline & & & & & & & KPC & 84 & 84 & $100 \%$ \\
\hline & & & & & & & IMP & 1 & 1 & $100 \%$ \\
\hline \multirow{5}{*}{ Moore [11] } & \multirow{5}{*}{2017} & \multirow{5}{*}{ prospective } & \multirow{5}{*}{$\begin{array}{l}\text { culture and } \\
\text { sequence }\end{array}$} & \multirow{5}{*}{ France } & \multirow{5}{*}{$\begin{array}{c}755 \text { clinical isolates } \\
\text { and } 432 \text { contrived } \\
\text { isolates }\end{array}$} & \multirow{5}{*}{1187} & OXA-48 & 113 & 111 & $98.23 \%$ \\
\hline & & & & & & & NDM & 88 & 88 & $100 \%$ \\
\hline & & & & & & & VIM & 92 & 87 & $94.57 \%$ \\
\hline & & & & & & & KPC & 110 & 110 & $100 \%$ \\
\hline & & & & & & & IMP & 80 & 76 & $95 \%$ \\
\hline \multirow{5}{*}{$\begin{array}{l}\text { Findlay } \\
{[14]}\end{array}$} & & & & & 450 isolates cultured & & OXA-48 & 100 & 100 & $100 \%$ \\
\hline & & & & & from 2808C freezer & & NDM & 100 & 100 & $100 \%$ \\
\hline & 2015 & retrospective & in-house PCR & UK & $\begin{array}{l}\text { storage or from the } \\
\text { sender's original slopes }\end{array}$ & 450 & VIM & 100 & 100 & $100 \%$ \\
\hline & & & & & on MacConkey agar & & KPC & 100 & 100 & $100 \%$ \\
\hline & & & & & $\begin{array}{c}\text { plates with a } 10 \mathrm{mg} \\
\text { ertapenem disc }\end{array}$ & & IMP & 24 & 17 & $71 \%$ \\
\hline $\begin{array}{l}\text { Hoyos- } \\
\text { Mallecot }\end{array}$ & & & culture and & & 241 clinical icolates & & KPC & 1 & 1 & $100.00 \%$ \\
\hline [15] & 2017 & retrospective & sequence & USA and rtaly & 241 cimical isolates & 241 & OXA-48 & 10 & 10 & $100 \%$ \\
\hline & & & & & & & OXA-48 & 9 & 8 & $88.90 \%$ \\
\hline & & & determined by & & & & NDM & 25 & 25 & $100 \%$ \\
\hline Kost [16] & 2017 & retrospective & $\begin{array}{l}\text { PCR or whole } \\
\text { genome }\end{array}$ & $\begin{array}{l}\text { USA and } \\
\text { Europe }\end{array}$ & 96 clinical isolates & 96 & VIM & 3 & 3 & $100 \%$ \\
\hline & & & sequencing & & & & KPC & 43 & 41 & $95.30 \%$ \\
\hline & & & & & & & IMP & 2 & 2 & $100 \%$ \\
\hline & & & & & & & OXA-48 & 24 & 24 & $100 \%$ \\
\hline & & & in-house & & & & NDM & 22 & 22 & $100 \%$ \\
\hline [17] & 2018 & retrospective & susceptibility & USA & $\begin{array}{l}26 \text { clinical isolates and } \\
69 \text { screening samples }\end{array}$ & 95 & VIM & 19 & 19 & $100 \%$ \\
\hline & & & testing(AST) & & & & KPC & 3 & 3 & $100 \%$ \\
\hline & & & & & & & IMP & 1 & 1 & $100 \%$ \\
\hline & & & & & & & OXA-48 & 89 & 89 & $100 \%$ \\
\hline & & & & & & & NDM & 78 & 78 & $100 \%$ \\
\hline $\begin{array}{l}\text { I raczewsk1 } \\
{[18]}\end{array}$ & 2018 & retrospective & $\begin{array}{l}\text { culture and } \\
\text { sequence }\end{array}$ & USA & $\begin{array}{l}428 \text { clinical isolates } \\
\text { and } 57 \text { fresh isolates }\end{array}$ & 485 & VIM & 82 & 82 & $100 \%$ \\
\hline & & & & & & & KPC & 84 & 84 & $100 \%$ \\
\hline & & & & & & & IMP & 40 & 40 & $100 \%$ \\
\hline & & & & & & & OXA-48 & 10 & 10 & $100 \%$ \\
\hline & & & & & & & NDM & 11 & 11 & $100 \%$ \\
\hline Cointe [19] & 2019 & prospective & PCR & France & 53 clinical isolates & 53 & VIM & 7 & 7 & $100 \%$ \\
\hline & & & & & & & KPC & 10 & 10 & $100 \%$ \\
\hline & & & & & & & IMP & 1 & 1 & $100 \%$ \\
\hline
\end{tabular}


TABLE 4: The quality evaluation results for each study included in the meta-analysis.

\begin{tabular}{|c|c|c|c|c|c|c|c|c|c|c|c|c|}
\hline \multirow{2}{*}{ Author } & \multirow{2}{*}{ Year } & \multicolumn{11}{|c|}{ QUDAS-2 } \\
\hline & & 1 & 2 & 3 & 4 & 5 & 6 & 7 & 8 & 9 & 10 & 11 \\
\hline Tato [9] & 2016 & $\mathrm{Y}$ & $\mathrm{Y}$ & UC & UC & UC & $\bar{Y}$ & $\mathrm{UC}$ & $\mathrm{UC}$ & $\bar{Y}$ & $\mathrm{Y}$ & $\bar{Y}$ \\
\hline McMullen [10] & 2017 & $\mathrm{~N}$ & $\mathrm{~N}$ & $\mathrm{Y}$ & $\mathrm{N}$ & UC & $\mathrm{Y}$ & $\mathrm{Y}$ & $\mathrm{Y}$ & $\mathrm{Y}$ & $\mathrm{N}$ & $\mathrm{Y}$ \\
\hline Moore [11] & 2017 & $\mathrm{~N}$ & $\mathrm{Y}$ & $\mathrm{Y}$ & UC & UC & $\mathrm{Y}$ & UC & UC & $\mathrm{N}$ & $\mathrm{Y}$ & $\mathrm{N}$ \\
\hline Findlay [14] & 2015 & $\mathrm{Y}$ & $\mathrm{Y}$ & UC & $\mathrm{N}$ & UC & $\mathrm{Y}$ & $\mathrm{Y}$ & $\mathrm{Y}$ & $\mathrm{Y}$ & $\mathrm{Y}$ & $\mathrm{N}$ \\
\hline Hoyos-Mallecot [15] & 2017 & $\mathrm{Y}$ & UC & $\mathrm{N}$ & UC & UC & $\mathrm{Y}$ & UC & $\mathrm{Y}$ & $\mathrm{Y}$ & $\mathrm{Y}$ & $\mathrm{Y}$ \\
\hline Kost $[16]$ & 2017 & UC & $\mathrm{N}$ & $\mathrm{N}$ & $\mathrm{N}$ & UC & $\mathrm{Y}$ & $\mathrm{Y}$ & $\mathrm{Y}$ & $\mathrm{Y}$ & $\mathrm{N}$ & $\mathrm{N}$ \\
\hline Vanstone [17] & 2018 & $\mathrm{Y}$ & $\mathrm{Y}$ & UC & $\mathrm{N}$ & UC & $\mathrm{Y}$ & $\mathrm{Y}$ & $\mathrm{Y}$ & $\mathrm{Y}$ & $\mathrm{Y}$ & $\mathrm{N}$ \\
\hline Traczewski [18] & 2018 & $\mathrm{Y}$ & $\mathrm{Y}$ & UC & $\mathrm{N}$ & UC & Y & $\mathrm{Y}$ & $\mathrm{Y}$ & $\mathrm{Y}$ & $\mathrm{Y}$ & $\mathrm{N}$ \\
\hline Cointe [19] & 2019 & $\mathrm{~N}$ & $\mathrm{~N}$ & UC & $\mathrm{N}$ & $\mathrm{UC}$ & $\mathrm{Y}$ & $\mathrm{Y}$ & $\mathrm{Y}$ & $\mathrm{Y}$ & $\mathrm{Y}$ & $\mathrm{Y}$ \\
\hline
\end{tabular}

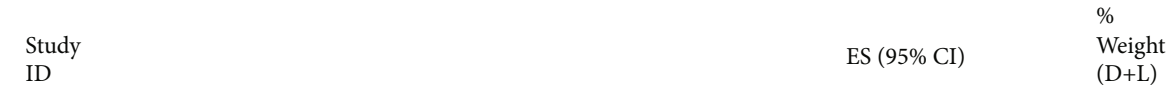

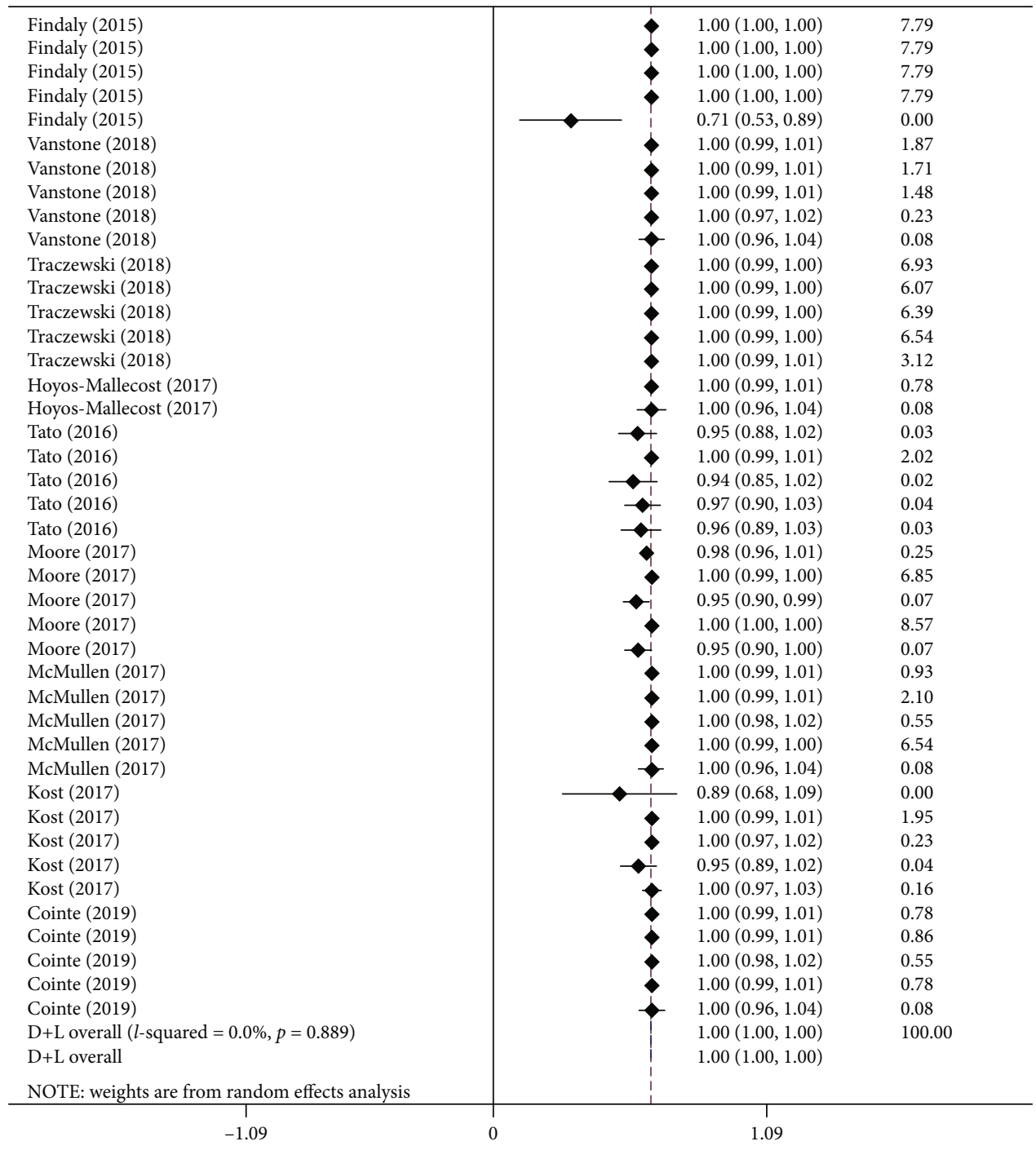

FIGURE 1: Forest map for the analysis of the carbapenemase gene Identification ratio at the genetic level. 


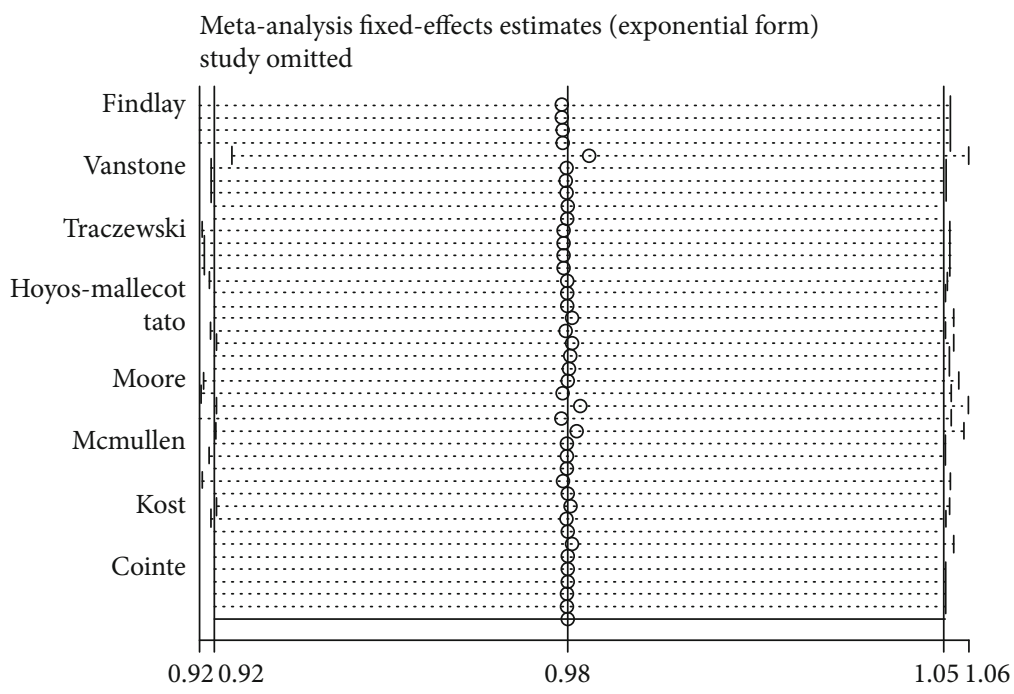

FIGURE 2: Sensitivity analysis of carbapenemase genes.

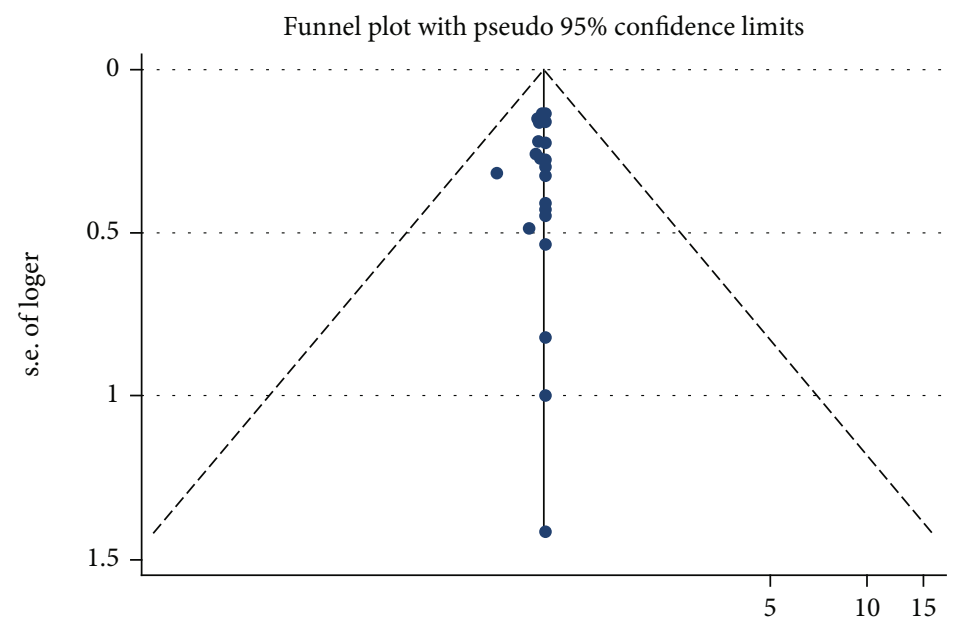

The correct of identification ratio

FIGURE 3: Funnel plot incorporating carbapenemase genes.

screening based on the formerly established inclusion and exclusion criteria, 9 articles were finally selected and data extracted from them were processed and analyzed with the designated statistical software. The final results show that Xpert Carba-R assay performs a $100 \%\left(p=0.889\right.$ and $I^{2}=$ $0.0 \%$ ) accuracy, which justifies that it is a well-suited method for the detection of carbapenemase genes. In this study, the "big five" families of carbapenemase genes, namely, OXA48, KPC, IMP, NDM, and VIM were investigated. In the process of literature review, Xpert Carba- $\mathrm{R}$ assay turned out to detect two carbapenemase genes in the same sample simultaneously, such as OXA-48-NDM, OXA-48-KPC [24], KPC-2VIM-1, and IMP-1-VIM-1 [25]. However, due to strong randomness of these cases and for the accuracy of scientific research, there will be no further elaboration on that in this article. What is more, Xpert Carba-R assay is highly inclusive in terms of the source of samples, by which the authors mean that various types of clinical specimens could serve as the samples, including urine, blood, body fluid, respiratory tract sampling., and rectal swab [10]. In Hoyos-Mallecot et al.'s study, in view of diagnostic accuracy, Xpert Carba- $\mathrm{R}$ assay behaves even better than the gold standard [15]. However, for the sake of the rigorousness of statistical analysis, data were still extracted based on the results of gold standard test.

From another perspective, Xpert Carba-R assay has certain limitations. For instance, Xpert Carba-R assay could not identify some subtypes of genes. To name a case in point, in Findlay et al.'s study, Carba-R assay cannot identify OXA181 , one of the subtypes of the OXA-48 family [14], and it is the same case with OXA-232 [9]. This may be a result of the imperfections of the technology corresponding to the database. Another limitation of Xpert Carba-R assay lies in that although Xpert Carba-R assay could effectively detect various types of samples, the samples must be cultured in advance [9]. At the same time, the decrease of the positive rate may also be due to the low bacterial load of the samples [12]. 
Moreover, different types of samples are always accompanied with varied sensitivities of the tests [21], which are the problems that await more advanced Xpert Carba-R assay to solve.

A subgroup analysis of the "big five" family of carbapenemase genes was performed to explore the heterogeneity of the studies. The detection rates of OXA-48, NDM, and KPC are all $100 \%\left(I^{2}=0.0 \%\right)$, which was mentioned in the previous part of this article, indicating that there is no heterogeneity. In the VIM and IMP families, the detection rate of the former is $100 \%\left(I^{2}=3.5 \%\right)$, signifying a low heterogeneity that can be ignored; the detection rate of the latter is $99 \%\left(I^{2}=52.6\right.$ $\%), 50 \%<52.6 \%<75 \%$, revealing moderate heterogeneity in this subgroup. The overall rate of carbapenemase gene detection is $100 \%\left(p=0.886\right.$ and $\left.I^{2}=0.0 \%\right)$, which indicates that the source of heterogeneity in this study was not a grouping factor. By analyzing the source literature where the data of the IMP subgroup coming from, it is speculated that the source of heterogeneity of this subgroup may be related to different gold standards for the selection of studies, a lack of continuity in the adoption of strain samples, variety of the types of samples, and some human factors [9-11, 1420]. For example, the IMP samples in Findlay et al.'s study were obtained randomly based on geographical factors, which may lead to heterogeneity within the subgroup [14].

The analytic results of this research show the influence of carbapenemase gene levels distributed in both sides of the shaft (0.98), not more than 95\% confidence interval $(0.92$ and 1.05), suggesting that there is no single study overall consolidation effect. In Egger's inspection, when $p>|0.1|$, there is no publication bias. The results of this study display that the overall $p=0.728$, which suggests a mild publication bias and is accepted in corresponding studies.

This research also has some limitations. As mentioned above, due to the strong randomness, only the data of detecting the "big five" family of carbapenemase genes were included, without the data of other families and the doubledetection types. In another respect, because of the imperfections of the corresponding database, the instrument models employed in the studies included in this research could not be analyzed, which is also a defect of our research.

In summary, Xpert Carba-R assay presents a high accuracy in the determination of the "big five" carbapenemase gene families in GNB, together with other merits of simple operation, low price, and less turnaround time. It is a good epidemiological tool for early clinical diagnosis and the prevention of the abuse of antibiotics. With the development of the follow-up versions, Carba-R assay may be an increasingly important diagnostic tool.

\section{Conclusions}

This project carried out an investigation of the accuracy of Xpert Carba-R assay in detecting the "big five" carbapenemase gene families in GNB and came to the conclusion that it could work as a new clinical diagnostic tool and the gold standard. This method has been proved reliable and efficient to detect five important carbapenemase gene families of OXA-48, IMP, NDM, KPC, and VIM. It can be seen that Xpert Carba- $\mathrm{R}$ method is an effective tool for early clinical detection, which is suitable for the detection of carbapenase gene in GNB.

\section{Data Availability}

The data in this study are obtained from the cited literature and have been noted in the manuscript.

\section{Conflicts of Interest}

The authors declare that they have no competing interests.

\section{Authors' Contributions}

XG Guo conceived and designed the experiments. HH Li, ZJ He, LM Xie, and JS Zhang analyzed the studies and extracted data. $\mathrm{HH} \mathrm{Li}$ and $\mathrm{ZJ} \mathrm{He}$ contributed to the formation of figures. $\mathrm{HH} \mathrm{Li}, \mathrm{ZJ} \mathrm{He}$, LM Xie, SJ Fan, and TA Xie contributed to the production of tables. All authors participated in the writing, reading, and revising of the manuscript and approved the final version of the manuscript. Hou-He $\mathrm{Li}$ and Zhi-Jian He contributed equally to this work.

\section{Acknowledgments}

Our sincere gratitude goes to all the members of the team for their whole-hearted cooperation and to the reverend authors of the studies included in this research for their excellent work and valuable participation.

\section{Supplementary Materials}

S1 Flow diagram of study identification and inclusion. (Supplementary Materials)

\section{References}

[1] R. A. Bonomo, E. M. Burd, J. Conly et al., "Carbapenemaseproducing organisms: a global scourge," Clinical Infectious Diseases, vol. 66, no. 8, pp. 1290-1297, 2018.

[2] A. M. Queenan and K. Bush, "Carbapenemases: the versatile beta-lactamases," Clinical Microbiology Reviews, vol. 20, no. 3, pp. 440-458, 2007.

[3] T. R. Walsh, M. A. Toleman, L. Poirel, and P. Nordmann, "Metallo-beta-lactamases: the quiet before the storm?," Clinical Microbiology Reviews, vol. 18, no. 2, pp. 306-325, 2005.

[4] Centers for Disease Control and Prevention (CDC), "Vital signs: carbapenem-resistant Enterobacteriaceae," $M M W R$ Morbidity Mortality Weekly Report, vol. 62, pp. 165-170, 2013.

[5] S. L. Solomon and K. B. Oliver, "Antibiotic resistance threats in the United States: stepping back from the brink," American Family Physician, vol. 89, no. 12, pp. 938-941, 2014.

[6] J. S. Esterly, J. Wagner, M. M. McLaughlin, M. J. Postelnick, C. Qi, and M. H. Scheetz, "Evaluation of clinical outcomes in patients with bloodstream infections due to Gram-negative bacteria according to carbapenem MIC stratification," Antimicrobial Agents and Chemotherapy, vol. 56, no. 9, pp. 4885-4890, 2012.

[7] K. F. Anderson, D. R. Lonsway, J. K. Rasheed et al., "Evaluation of methods to identify the Klebsiella pneumoniae carbapenemase in Enterobacteriaceae," Journal of Clinical Microbiology, vol. 45, no. 8, pp. 2723-2725, 2007. 
[8] L. L. Baeza, N. Pfennigwerth, C. Greissl et al., "Comparison of five methods for detection of carbapenemases in Enterobacterales with proposal of a new algorithm," Clinical Microbiology and Infection, vol. 25, no. 10, pp. 1286.e9-1286.e15, 2019.

[9] M. Tato, P. Ruiz-Garbajosa, M. Traczewski et al., "Multisite evaluation of Cepheid Xpert Carba-R assay for detection of carbapenemase-producing organisms in rectal swabs," Journal of Clinical Microbiology, vol. 54, no. 7, pp. 1814-1819, 2016.

[10] A. R. McMullen, M. L. Yarbrough, M. A. Wallace, A. Shupe, and C. D. Burnham, "Evaluation of genotypic and phenotypic methods to detect carbapenemase production in Gramnegative bacilli," Clinical Chemistry, vol. 63, no. 3, pp. 723730, 2017.

[11] N. M. Moore, R. Cantón, E. Carretto et al., "Rapid identification of five classes of carbapenem resistance genes directly from rectal swabs by use of the Xpert Carba-R assay," Journal of Clinical Microbiology, vol. 55, no. 7, pp. 2268-2275, 2017.

[12] M. Zhou, T. Kudinha, B. du et al., "Active surveillance of carbapenemase-producing organisms (CPO) colonization with Xpert Carba- $\mathrm{R}$ assay plus positive patient isolation proves to be effective in CPO containment," Frontiers in Cellular and Infection Microbiology, vol. 9, p. 162, 2019.

[13] P. F. Whiting, A. W. Rutjes, M. E. Westwood et al., "QUADAS-2: a revised tool for the quality assessment of diagnostic accuracy studies," Annals of Internal Medicine, vol. 155, no. 8, pp. 529-536, 2011.

[14] J. Findlay, K. L. Hopkins, D. Meunier, and N. Woodford, "Evaluation of three commercial assays for rapid detection of genes encoding clinically relevant carbapenemases in cultured bacteria," Journal of Antimicrobial Chemotherapy, vol. 70, no. 5, pp. 1338-1342, 2015.

[15] Y. Hoyos-Mallecot, S. Ouzani, L. Dortet, N. Fortineau, and T. Naas, "Performance of the Xpert ${ }^{\circledR}$ Carba-R v2 in the daily workflow of a hygiene unit in a country with a low prevalence of carbapenemase-producing Enterobacteriaceae," International Journal of Antimicrobial Agents, vol. 49, no. 6, pp. 774-777, 2017.

[16] K. Kost, J. Yi, B. Rogers, and R. Jerris, "Comparison of clinical methods for detecting carbapenem-resistant Enterobacteriaceae," Practical Laboratory Medicine, vol. 8, pp. 18-25, 2017.

[17] G. L. Vanstone, S. Woodhead, K. Roulston et al., "Improving the detection of carbapenemase-producing organisms (CPO) in a low-prevalence setting: evaluation of four commercial methods and implementation of an algorithm of testing," Journal of Medical Microbiology, vol. 67, no. 2, pp. 208-214, 2018.

[18] M. M. Traczewski, E. Carretto, R. Canton, N. M. Moore, and for the Carba-R Study Team, "Multicenter evaluation of the Xpert Carba-R assay for detection of carbapenemase genes in Gram-negative isolates," Journal of Clinical Microbiology, vol. 56, no. 8, article e00272, 2018.

[19] A. Cointe, V. Walewski, C. A. Hobson et al., "Rapid carbapenemase detection with Xpert Carba-R V2 directly on positive blood vials," Infection and Drug Resistance, vol. 12, pp. 33113316, 2019.

[20] G. Regev-Yochay, G. Smollan, I. Tal et al., "Sink traps as the source of transmission of OXA-48-producing Serratia marcescens in an intensive care unit," Infection Control and Hospital Epidemiology, vol. 39, no. 11, pp. 1307-1315, 2018.

[21] H. A. Terzi, O. Aydemir, U. Kilic et al., "Comparison of the Xpert CARBA-R test and phenotypical tests for detection of carbapenemases types in multidrug resistant $\mathrm{K}$. pneumoniae isolates," Clinical Laboratory, vol. 65, no. 8, 2019.
[22] S. Anandan, S. Damodaran, R. Gopi, Y. D. Bakthavatchalam, and B. Veeraraghavan, "Rapid screening for carbapenem resistant organisms: current results and future approaches," Journal of Clinical and Diagnostic Research, vol. 9, pp. DM01DM03, 2015.

[23] J. W. Teo, S. Octavia, J. W. Cheng, and R. T. Lin, "Evaluation of an in-house developed multiplex real-time PCR for the detection of IMP, OXA-23, GES carbapenemases and the transmissible colistin-resistant_mcr_gene on the BD MAX ${ }^{\mathrm{TM}}$ open system," Diagnostic Microbiology and Infectious Disease, vol. 90, no. 1, pp. 67-69, 2018.

[24] A. Baicus, B. Lixandru, M. Stroia et al., "Antimicrobial susceptibility and molecular epidemiology of carbapenem-resistant Klebsiella pneumoniae strains isolated in an emergency university hospital," Romanian Biotechnological Letters, vol. 23, 2018.

[25] M. Smith, B. Diederen, J. Scharringa, M. Leversteijn-van Hall, A. C. Fluit, and J. Cohen Stuart, "Rapid and accurate detection of carbapenemase genes in Enterobacteriaceae with the Cepheid Xpert Carba-R assay," Journal of Medical Microbiology, vol. 65, no. 9, pp. 951-953, 2016. 